\title{
IMPACT OF PLANTER CLOSING WHEELS ON CORN EMERGENCE IN NO-TILL SYSTEMS
}

\author{
J. L. Drewry, B. D. Luck, F. J. Arriaga
}

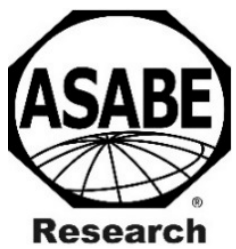

\section{HighLIGHTS}

- Aftermarket closing wheels increased corn emergence by $2 \%$ over standard rubber wheels.

- Yield was not significant by closing wheel type.

ABSTRACT. Producers are increasingly adopting cover crops and no-till planting for a variety of reasons including improving soil fertility and reducing energy inputs. However, adopting these practices may require changes in equipment and management strategy; therefore, research is needed to develop best practices for producers to reduce the risk and encourage adoption. The use of aftermarket closing wheels has been cited as a method to improve emergence under no-till conditions as preparing an ideal seedbed can be more difficult under these conditions due to limited seed-soil contact and side wall compaction. The effect of three aftermarket and the standard rubber closing wheels on emergence and yield under no-till planting of corn into heavy crop residue or cover crops was measured at three Wisconsin locations using a randomized complete block experimental design. Soil temperature and moisture was also monitored during the growing season. Corn plant emergence was measured at least three times to estimate the rate of emergence as a function of growing degree units using air and soil temperatures. The final emergence of corn planted with an aftermarket wheel was found to be significantly higher than the standard rubber closing wheel $(p=0.069, \alpha=0.1)$ across all locations. Yield was not found to be significant by wheel type most likely due to differences in field history and in season management practices.

Keywords. Closing wheel, Cover crop, Emergence, No-till, Planter set-up.

$\mathrm{T}$ The challenge of increasing agricultural production to feed a growing world population under increasing climatic variability requires attention. Conservation agriculture $(\mathrm{CA})$ has been cited as a method to improve soil fertility and reduce energy inputs (Triplett and Dick, 2008). However, adopting CA requires a change in management practices by producers and research is still needed to develop detailed best management practices for producers to reduce the risk in changing land management style and encourage adoption.

The three tenants of conservation agriculture: soil cover, minimal soil disturbance, and crop rotations aim to promote sustainable and profitable agriculture (FAO, 2013). Cover crops can provide soil cover and provide a host of benefits such as suppressing pests, improving soil health, and

The authors have paid for open access for this article. This work is licensed under a Creative Commons AttributionNonCommercial-NoDerivatives 4.0 International License https://creative commons.org/licenses/by-nc-nd/4.0/.

Submitted for review in February 2020 as manuscript number MS 13957; approved for publication as a Research Article by the Machinery Systems Community of ASABE in August 2020.

The authors are Jessica. L. Drewry, Assistant Faculty Associate, Brian D. Luck, Assistant Professor and Extension Specialist, Department of Biological Systems Engineering, University of Wisconsin-Madison, Madison, Wisconsin; and Francisco J. Arriaga, Associate Professor, Department of Soil Science, University of Wisconsin-Madison, Madison, Wisconsin. Corresponding author: Brian D. Luck, 460 Henry Mall, Madison, WI 53706; phone: 608-890-1861; e-mail: bluck@wisc.edu. increasing nutrient cycle efficiency (Snapp et al., 2005). Adopting no-till practices minimizes soil disturbance except around the seed, which maintains the soil structure. In addition, eliminating tillage can reduce fuel usage by up to $46 \%$ over conventional tillage in the Northern Corn Belt (https://ecat.sc.egov.usda.gov). Practicing crop rotations can reduce pests and weeds, and allow the soil to recover from high nutrient demand crop production (Bullock, 1992; Liebman and Dyck, 1993).

The tenants of CA must be adopted in combination to maintain crop yields (Pittelkow et al., 2015). This is especially critical in corn where yield decreases have been seen under no-till practices (Pedersen and Lauer, 2003) or after cover crops (Pantoja et al., 2015). Research has not yet been able to determine whether yield losses are due to biophysical conditions or inadequate management practices (Pittelkow et al., 2015).

Conventional planter equipment and configurations were not designed to accommodate the crop residues left on the field surface when practicing CA. This can lead to poorly closed furrows, improper planting depth, residue incorporated into the furrow, seeds dislodged from the furrow, etc. Which in turn can lead to within row variability of corn plant emergence which has been shown in multiple studies to negatively impact yield ( Nafziger et al., 1991; Ford and Hicks, 1992; Martin et al., 2005). In addition, the cover crops and crop residue that provide the soil cover can decrease early season soil temperature (Wolkowski, 2000) which can lead 
to delayed emergence in no-till for continuous corn (Vetsch and Randall, 2002). Overcoming these stresses could help to close the yield gap between conventional tillage and no-till practices.

Closing wheels cover the furrow with soil once the seed has been dropped into the furrow. Closing wheel performance can be affected by soil type, soil moisture conditions, and level of residue remaining from the previous crop or cover crop. The type of closing wheel and the down pressure used during operation can have an effect on soil compaction (Stephens and Johnson, 1993). After-market closing wheels have been developed to improve seedbed conditions by improving furrow closing, reducing sidewall compaction, and improving soil-seed contact. However, some of these manufacturer claims have not been thoroughly evaluated.

Industry studies from Beck's Hybrids cite increases of up to $6.8 \mathrm{bu} /$ acre in corn yield but do not provide any details on experimental design or statistical results (https://www.beckshybrids.com/pfresearch/). A multi-year study in corn found no difference in final stand count as a function of closing wheel type (Hanna et al., 2015). A study in cotton found no effect of planter closing wheels on emergence 10 days after planting in a conservation tillage system (Way et al., 2018). However, the authors noted that dry conditions in year two of the study may have impacted the results (Way et al., 2018).

As of 2015, approximately $40 \%$ of farmland was no-till and cover crops were used on only $2 \%$ of farmland (Wade et al., 2015). Some studies have cited lack of knowledge or visibility as negative factors in the adoption of these practices (Baumgart-Getz et al., 2012; Reimer et al., 2012). Extension publications have cited the need for careful selection and adjustment of planter attachments but do not provide further guidelines (Abrameit et al., 2006; Al-Kaisi et al., 2008). Applied research to assess planter set-up for no-till planting into cover crops is needed to provide producers detailed recommendations. Thus, the objective of this research project was to assess the effect of closing wheel type on corn plant emergence when no-till planting into cover crops.

\section{MATERIALS AND MethodS}

In 2017, corn (Zea mays) was planted at three locations (Dane, Marathon, and Rock Counties) throughout Wisconsin that were selected to capture a range of climates and soil types within the state. All soils in this study were derived from loess underlain by glacial material, which is typical of many soils in the region. Given the loess cap on these soils, the texture of the top soil is silt loam. However, there are differences in drainage capabilities between them, with the soils at the Dane and Rock Co. sites being well drained while the soil at Marathon Co. is somewhat poorly drained. Differences in drainage capabilities are caused by a mixture of glacial till with an argillic horizon at about $1 \mathrm{~m}$ of depth at the Marathon Co. site, while the other two sites have a sandy till residue underlying deeper in the soil profile. Further, the soil at the Dane Co. site had greater slope, making it likely that erosion that occurred in the past exposed some of the lower clay subsoil layers. Another key distinction between these sites is that the Dane and Rock Co. sites have an average accumulated growing degree days (GDD) of about 2,500 GDD, while the Marathon Co. site has approximately 400 GDD less (Laboski and Peters, 2012). Additionally, there were some differences in management between locations. The Dane Co. had been in a conventionally tilled alfalfa rotation prior to the study, the Marathon Co. had heavy alfalfa residue terminated prior to planting, and the Rock Co. contained corn residue from the previous year's conventionally tilled planting. Differences in soil and other factors between these sites provided a good range of conditions in which to test the performance of the different closing wheel systems.

Soil temperature (Extremal Temperature Sensor, Spectrum Technologies, Inc., Aurora, Ill.) and soil moisture (WaterScout SM100, Spectrum Technologies, Inc.) were monitored (WatchDog1000, Spectrum Technologies Inc.) after planting until harvest at 1 hour intervals at the target plating depth at a central location in the plots between two rows.

Four closing wheels were selected for testing based on the recommendations of county-based extension agents and farmer-led watershed conservation groups familiar with aftermarket closing wheels and Wisconsin soils. The standard rubber closing wheel (John Deere, Moline, Ill.), a curved closing wheel (Curvetine, Dawn Equipment Co. Sycamore, Ill.), a spiked closing wheel (Martin Industries, Elkton, Ky.), and a cast iron paddle closing wheel (Yetter Farm Equipment, Colchester, Ill.). Each wheel was mounted to the spring-loaded wheel arm, the spacing between wheels set to manufactures recommendations, and the down force on the wheel set to the lightest setting at all locations.

The 4-row, 3-point hitch mounted planter (7000, John Deere, Moline, Ill.) was equipped with a hydraulically driven variable rate seeding technology and down pressure was controlled by air bags on each row unit, figure 1. Each row unit was equipped with row cleaners, a 13 fluted wavy no-till coulter, and double disk opener. The down pressure on each closing wheel was held at the same level and the gauge wheels were adjusted at each location to achieve the appropriate planting depth for the given soil and residue

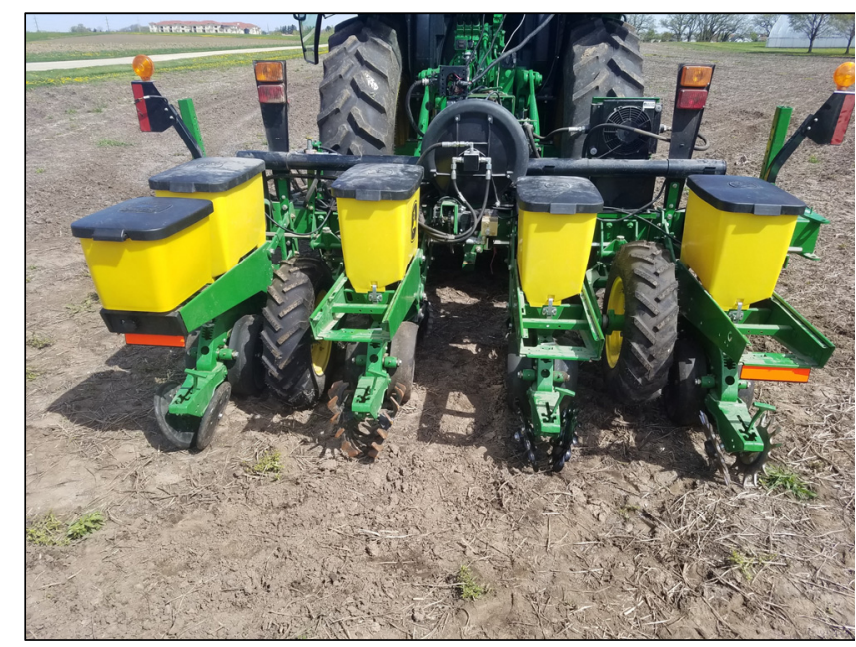

Figure 1. 4-row planter (John Deere 7000) used in the experiment with one set of closing wheels installed on each row. 
conditions, between 5 and $7 \mathrm{~cm}$. This target seeding depth was verified for each row within the border rows surrounding the plots so that data generating plots were not disturbed. Planter passes were approximately $24 \mathrm{~m}$ minimum length and each plot was surrounded by at least eight border rows. All planting operations were conducted at $2.2 \mathrm{~m} \mathrm{~s}^{-1}$. The southern locations (Dane and Rock Co.) were planted with Pioneer ${ }^{\mathrm{TM}}$ P0339AMXT and northern location (Marathon Co.) was planted with Tracy Seeds T086-26 GTA at a population of 88,889 seeds ha ${ }^{-1}$ on $76 \mathrm{~cm}$ rows. The seeding rate was verified prior to planting by visual inspection of the number of seeds in 1/1000 of an acre. Standard agronomic practices were used, including fertilizer and pesticide applications, during the growing season at the producer's or research station's discretion.

\section{EMERGENCE AND YIELD}

Emergence of corn plants was determined in $3 \mathrm{~m}$ sections in the middle of each row at all locations. Emergence was counted a minimum of three times prior to vegetative state 3 (V3) at locations to determine emergence rate. Marathon and Rock County locations were harvested with a plot combine. Moisture content and plot length were used to determine the final yield at $15.5 \%$ moisture. Dane County plots were harvested by hand on 1/1000 acre for each row then shelled with a mechanical sheller and adjusted for moisture at time of shelling to determine final yield at $15.5 \%$ moisture. Only the center two rows were considered in the yield analysis as an automatic steering system was not used when planting the plots.

\section{Statistical ANALYsis}

A randomized complete block design was employed to test the performance of closing wheels at each location under no-till conditions into crop residue or cover crops. A pair of each closing wheel was installed on a single row for each planter pass (plot) within the field. For every plot, the row on which each set of closing wheel was installed was randomized to account for variations in seeding depth, down pressure between individual rows, and residue quantity among plots. A minimum of 30 replications were performed at each location. A mixed model was used to determine the effect of closing wheel on emergence, assumptions of normality and constant variance of the residuals were assessed graphically. Block, across all locations, was modeled as random effect. Significance was assessed at $\alpha=0.1$.

\section{RESULTS AND DISCUSSION}

Soil moisture sensors recorded regular rainfall and soil moisture conditions within an ideal range over the early growing season. Soil moisture content recorded at planting was $21 \%, 21 \%$, and $26 \%$ in Dane, Rock, and Marathon Counties, respectively, based on oven dying of three samples taken within the field at planting depth (ASTM, 2005). The soil moisture content at the time of planting presented conditions conducive for the seed furrow to stay open (Iqbal et al., 1998), proving good context to compare the closing wheels. Rainfall at all locations was above historical average during the 2017 growing season (http://www.aos.wisc.edu/ sco/); therefore, soil moisture should not have been a limiting factor in corn emergence. Rock and Dane counties were cool in the early season, while Marathon County was unseasonably warm which lead to faster emergence. In Marathon County most all plants were emerged 9 days after planting. In Dane and Rock Counties, fewer than $50 \%$ of the plants were emerged 10 days after planting. Differences in emergence rates between sites are likely due to differences in temperature and corn varieties.
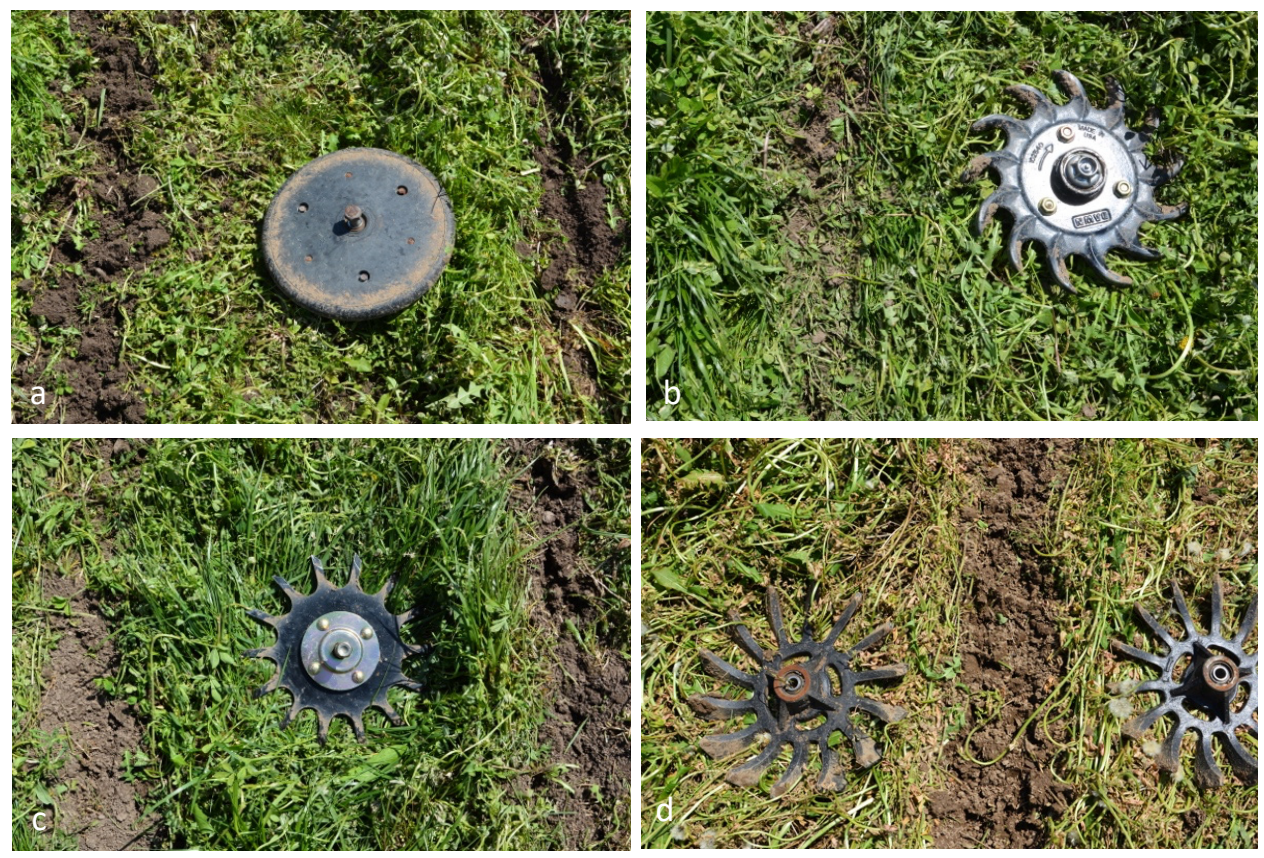

Figure 2. Example of seedbed just after planting into terminated alfalfa in Marathon Co. with the (a) standard, (b) curved, (c) spiked, and (d) paddle closing wheels. 
Table 1. Final emergence and yield by closing wheel.

\begin{tabular}{cccccc}
\hline & \multicolumn{2}{c}{ Emergence $(\%)$} & & \multicolumn{2}{c}{ Yield $(\mathrm{Mg} / \mathrm{ha})$} \\
\cline { 2 - 3 } \cline { 5 - 6 } Wheel & Mean & SD & & Mean & SD \\
\hline Standard & 97.3 & 9.3 & & 13.6 & 3.4 \\
Paddle & 95.5 & 8.3 & & 14.0 & 3.4 \\
Curved & 98.2 & 8.8 & & 13.5 & 3.6 \\
Spiked & 97.0 & 9.2 & & 13.4 & 3.4 \\
\hline
\end{tabular}

All aftermarket wheel and row cleaners created some disturbance to soil in the planting bed, figure 2. This removed the cover crop or plant residue around the bed and loosened the surrounding soil which potentially, increased soil temperatures and reduced sidewall compaction. This effect was observed to a lesser degree for the rubber wheel where this effect was only produced by the row cleaners. Some variability in emergence could be due to variation in residue/ cover crop within and between plots that could lead to nonuniform seed depth and placement.

Final emergence of closing wheels by location is summarized in table 1 for the 348 rows measured across the three

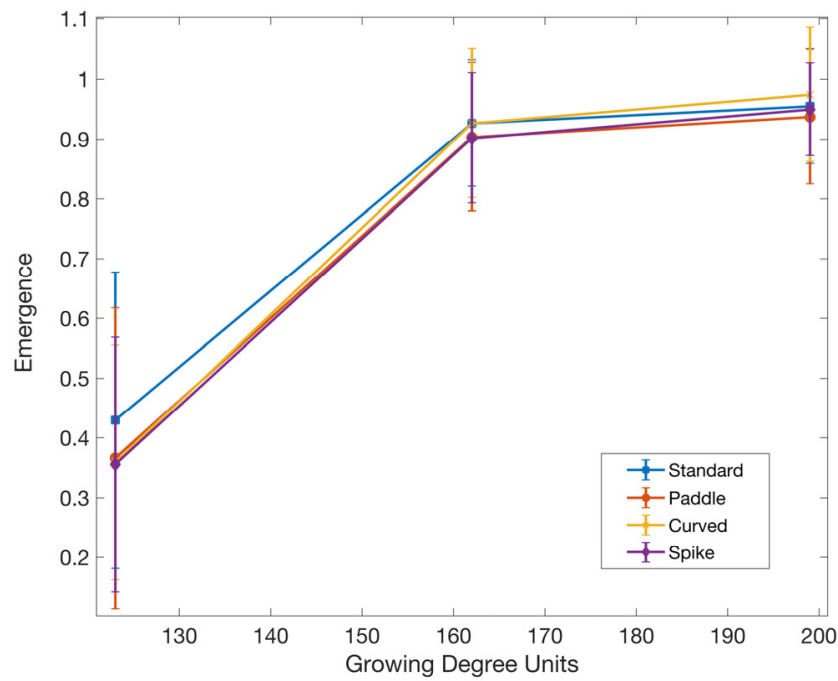

(a) locations. While no individual closing wheel had statistically significant higher emergence, the Curved wheel had the highest emergence, numerically, across all locations at 98.2\%. The highest overall emergence was the Paddle wheel in Marathon County at 99.6\%. In Rock and Marathon Counties emergence was numerically higher for aftermarket than standard closing wheels while no clear trend existed in Dane County (fig. 3).

As the closing wheels selected all had curved or spiked patterns, rather than smooth, they were grouped together for further statistical analysis. Emergence was significantly higher for aftermarket wheels as compared to the standard rubber wheel by $2 \%(\mathrm{p}=0.069)$. Other studies have not found significant differences between closing wheel types; however, these studies had a lower number of replicates than the current study or some unfavorable environmental conditions (Hanna et al., 2015; Way et al., 2018).

In addition, counts of emergence starting within the first week of spiking were collected to examine emergence rate

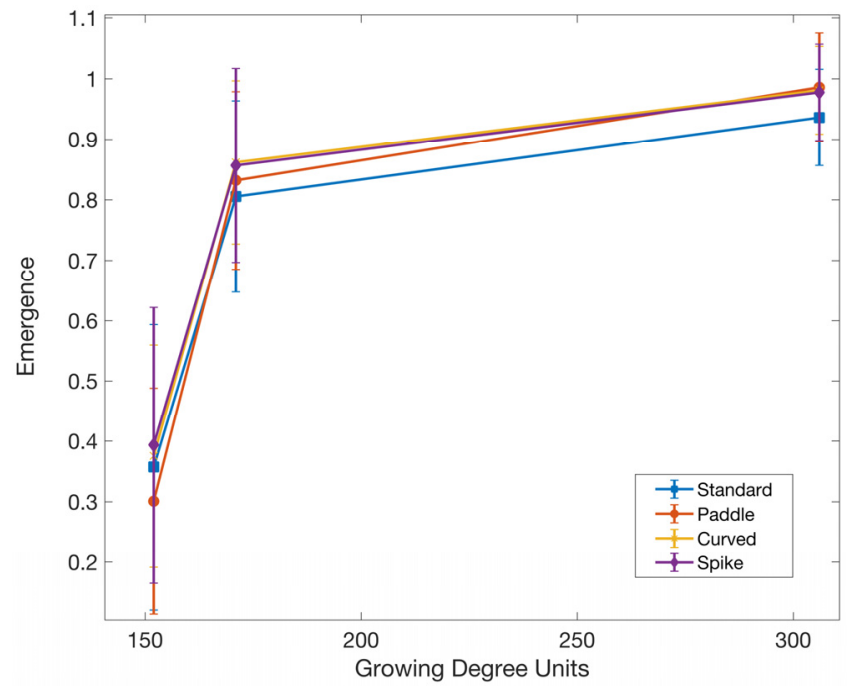

(b)

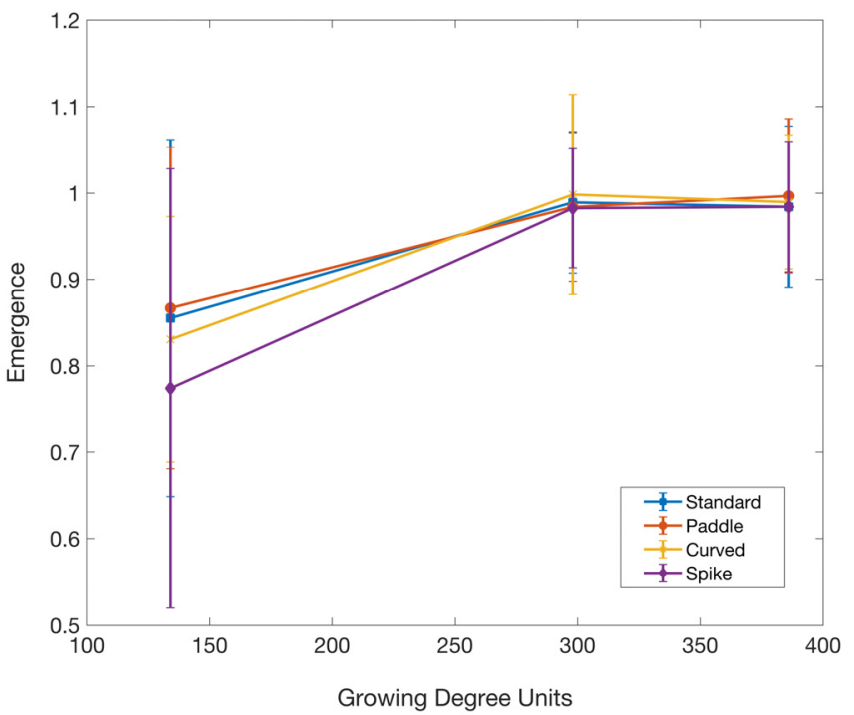

(c)

Figure 3. Emergence rate ( \pm SD) of corn as a function of growing degree units based on air temperature at the three plot locations: (a) Rock Co., (b) Dane Co., and (c) Marathon Co. 


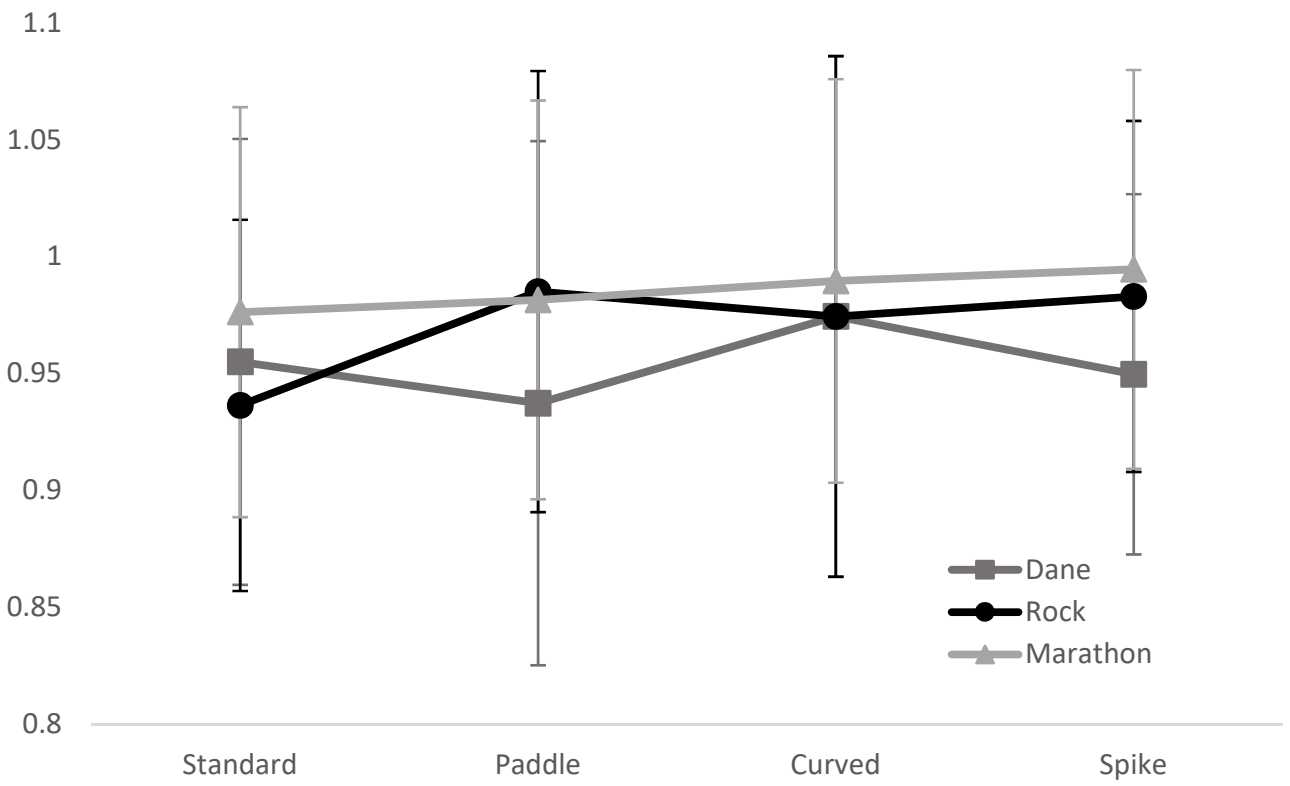

Figure 4. Final emergence ( \pm SD) as a function of closing wheel and location.

(fig. 3). There were different trends at each location but due to the large amount of variability no significant trends emerged (fig 4). During emergence, visual observations of furrow closure were also recorded. Treatments with the spiked closing wheel in Marathon Co. frequently split open and exposed the seed which may have caused the shallower slope of the emergence curve. This suggest that producers should be very careful in setting the down pressure on the closing wheel to ensure the furrow is closed under the specific soil conditions encountered. The down pressure applied to the more aggressive aftermarket closing wheels also controls the depth at which they interact with the furrow. Having the down pressure set too high could result in removing seed from the furrow. When using these types of wheels, farmers should check their performance often throughout a working day to ensure that soil types or conditions have not changed sufficiently enough to negatively impact seed placement and ensure the furrow is being closed properly.

Final yield of each $(\mathrm{N}=236)$ of the center two rows of plots was not significantly different by closing wheel type (standard vs. aftermarket) across all locations $(\mathrm{p}=0.88)$. Yield was significant by location $(\mathrm{p}<0.0001)$, but the interaction of wheel type and location was not $(p=0.63)$. Numerically, the paddle closing wheel had the highest yield of $14 \mathrm{Mg} \mathrm{ha}^{-1}$. However, considering only the center two rows of each plot and location as a factor reduced the power of the analysis. While all locations followed standard agronomic practices, the large amount of variability between plots could be attributed to different in season management, weather, and field histories. Additionally, stand variability within rows due to the challenges of no-till planting could account for differences in yield (Nafziger et al., 1991; Ford and Hicks, 1992; Martin et al., 2005).

\section{CONCLUSIONS}

In Wisconsin, aftermarket closing wheels increased corn emergence in no-till systems by $2 \%(p=0.069, \alpha=0.1)$ The effect on yield was not significant $(\mathrm{p}=0.52, \alpha=0.1)$ but may be attributed to different management strategies, field histories, and weather. However, great care should be taken in setting up the closing wheels to ensure the correct spacing between wheels and down pressure to ensure proper operation and furrow closure. The weight and aggressive nature of these aftermarket closing wheel systems can dislodge and remove seed from the furrow if not set correctly. This is especially important in moist fine-textured soils. Using manufacturer's recommendations for setup is a good starting point, but fine tuning the setup for specific soil types and conditions should be done once in the field and as field conditions change during planting. Future work will study the effect of other planter modifications such as hydraulic down force and starter fertilizer as additional management strategies to close the yield gap between conventional tillage and no-till practices.

\section{ACKNOWLEDGEMENTS}

Funding was provided by the Wisconsin Corn Promotion Board Research Program. The authors would also like to thank the farmer led Sugar River Watershed Conservation Group for the inspiration to research this topic.

\section{REFERENCES}

Abrameit, A., Stichler, C., \& McFarland, M. L. (2006). Best management practices for conservation/reduced tillage. Texas FARMER Collection.

Al-Kaisi, M., Hanna, H. M., \& Duffy, M. D. (2008). Resource conservation practices: Consideration in selecting no-till. 
ASTM. (2005). Standard test methods for laboratory determination of water (moisture) content of soil and rock by mass. D2216. ASTM Committee D-18 on Soil Rock.

Baumgart-Getz, A., Prokopy, L. S., \& Floress, K. (2012). Why farmers adopt best management practice in the United States: A meta-analysis of the adoption literature. J. Environ. Manag., 96(1), 17-25. https://doi.org/10.1016/j.jenvman.2011.10.006

Bullock, D. G. (1992). Crop rotation. Critical Rev. Plant Sci., 11(4), 309-326. https://doi.org/10.1080/07352689209382349

FAO. (2013). Policy support guidelines for the promotion of sustainable production intensification and ecosystem services. Rome, Italy: United Nations FAO. Retrieved from http://www.fao.org/3/a-i3506e.pdf

Ford, J. H., \& Hicks, D. R. (1992). Corn growth and yield in uneven emerging stands. J. Prod. Agric., 5(1), 185-188. https://doi.org/10.2134/jpa1992.0185

Hanna, H. M., Schweitzer, D. D., \& Licht, M. (2015). Tractor and planter adjustments to improve profitability. Proc. 27th Annual Integrated Crop Management Conf., (pp. 195-205). https://doi.org/10.31274/icm-180809-193

Iqbal, M., Marley, S. J., Erbach, D. C., \& Kaspar, T. C. (1998). An evaluation of seed furrow smearing. Trans. ASAE, 41(5), 12431248. https://doi.org/10.13031/2013.17289

Laboski, C. A. M., \& Peters, J. B. (2012). Nutrient application guidelines for field, vegetable, and fruit crops in Wisconsin. University of Wisconsin-Extension Publ. A2809.

Liebman, M., \& Dyck, E. (1993). Crop rotation and intercropping strategies for weed management. Ecol. Appl., 3(1), 92-122. https://doi.org/10.2307/1941795

Martin, K. L., Hodgen, P. J., Freeman, K. W., Melchiori, R., Arnall, D. B., Teal, R. K.,... Raun, W. R. (2005). Plant-to-plant variability in corn production. Agron. J., 97(6), 1603-1611. https://doi.org/10.2134/agronj2005.0129

Nafziger, E. D., Carter, P. R., \& Graham, E. E. (1991). Response of corn to uneven emergence. Crop Sci., 31(3), 811-815. https://doi.org/10.2135/cropsci1991.0011183X003100030053x

Pantoja, J. L., Woli, K. P., Sawyer, J. E., \& Barker, D. W. (2015). Corn nitrogen fertilization requirement and corn-soybean productivity with a rye cover crop. SSSAJ, 79(5), 1482-1495. https://doi.org/10.2136/sssaj2015.02.0084
Pedersen, P., \& Lauer, J. G. (2003). Corn and soybean response to rotation sequence, row spacing, and tillage system. Agron. J., 95(4), 965-971. https://doi.org/10.2134/agronj2003.0965

Pittelkow, C. M., Liang, X., Linquist, B. A., van Groenigen, K. J., Lee, J., Lundy, M. E.,... van Kessel, C. (2015). Productivity limits and potentials of the principles of conservation agriculture. Nature, 517(7534), 365-368. https://doi.org/10.1038/nature13809

Reimer, A. P., Weinkauf, D. K., \& Prokopy, L. S. (2012). The influence of perceptions of practice characteristics: An examination of agricultural best management practice adoption in two Indiana watersheds. J. Rural Studies, 28(1), 118-128. https://doi.org/10.1016/j.jrurstud.2011.09.005

Snapp, S. S., Swinton, S. M., Labarta, R., Mutch, D., Black, J. R., Leep, R.,... O’Neil, K. (2005). Evaluating cover crops for benefits, costs and performance within cropping system niches. Agron. J., 97(1), 322-332. https://doi.org/10.2134/agronj2005.0322

Stephens, L. E., \& Johnson, R. R. (1993). Soil strenght in the seed zone of several planting systems. SSSAJ, 57(2), 481-489. https://doi.org/10.2136/sssaj1993.03615995005700020031x

Triplett, G. B., \& Dick, W. A. (2008). No-tillage crop production: A revolution in agriculture! Agron. J., 100(S3), 153-165. https://doi.org/10.2134/agronj2007.0005c

Vetsch, J. A., \& Randall, G. W. (2002). Corn production as affected by tillage system and starter fertilizer. Agron. J., 94(3), 532-540. https://doi.org/10.2134/agronj2002.5320

Wade, T., Claassen, R. L., \& Wallander, S. (2015). Conservationpractice adoption rates vary widely by crop and region. Washington, DC: USDA, ERS.

Way, T. R., Kornecki, T. S., \& Tewolde, H. (2018). Planter closing wheel effects on cotton emergence in a conservation tillage system. Appl. Eng. Agric., 34(1), 177-186. https://doi.org/10.13031/aea.12256

Wolkowski, R. P. (2000). Row-placed fertilizer for maize grown with an in-row crop residue management system in southern Wisconsin. Soil Tillage Res., 54(1-2), 55-62. https://doi.org/10.1016/S0167-1987(99)00114-2 